\title{
A Study on the Utilization of Urban Garden Design Derived from the Traditional Farming Method Gyeonjongbeop from the Joseon Period: Focused on Imwongyeongjeji Bolliji
}

\author{
In-Kyoung Hong, Hyung-Kwon Yun*, Young Chae, Sang-Mi Lee, Young-Bin Jung, and Mi-Ra Lee \\ Researcher, Urban Agriculture Research Division, National Institute of Horticultural and Herbal Science, Wanju 55365, Korea
}

\section{ABSTRACT}

Background and objective: Traditional farming is winning recognition as a sustainable alternative farming method. As urban farming increases in South Korea, it is crucial to develop more sustainable farming techniques. Gyeonjongbeop is the traditional farming method introduced in the Joseon period. This study was conducted to propose a productive garden model suitable for urban farming through the interpretation of traditional farming methods contained in Imwongyeongjeji Bolliji and to test the model on an actual field.

Methods: Using the design and cropping system of Gyeonjongbeop as the research materials, we reviewed its tillage and cultivation and examined the applicability. We proposed a modified method by extracting parts applicable to urban farming. According to the methods, we created a garden with ridges and furrows, cultivated proper vegetables, and evaluated their growth. Results: Raphanus sativus, Allium fistulosum L., Brassica juncea, and Spinacia oleracea grown on ridges showed higher growth than those grown on a conventional flat field. The growth of Hordeum vulgare var. hexastichon and Triticum aestivum $\mathrm{L}$. on furrows was also slightly higher. This proved that the method could make up for the deficiencies of barley and wheat that are weak against winds and cold and are easily destroyed by the spring rains.

Conclusion: Ridge and furrow cultivation derived from Gyeonjongbeop can be an efficient urban farming system compared to the conventional cultivation in flat fields. The system can use fallow lands in winter for year-round urban farming. In addition, the application of the traditional farming system can enhance the humanistic value of urban farming.

Keywords: Daejeonbeop(Daitianfa), eco-friendly, garden model, traditional agricultural technology, urban agriculture

\section{Introduction}

Traditional agricultural technology refers to the spirits, techniques, values and methods inherited by applying, adapting, transforming or originally creating the perceptions, behaviors and technical patterns of agriculture that have been sustained for a long time based on the norms of groups, which have lived within the boundaries of a specific region, so that they are suitable for the natural conditions of the region (Guh, 2009). Traditional agricultural technology, which values the diversity of crops, is making the best use of available regional resources and transforming into life cycle agriculture, such as catch cropping (intercropping) or shift of crops (crop rotation), soil management using worms, pest control using natural enemies, and sowing crops using rainfall types in each season. They are winning recognition as sustainable alternative farming methods that guarantee ecological circularity and environmental friendliness (Park, 2004). In particular, as the role of urban gardens is becoming more important and urban residents participate more and more in urban agriculture, there is an urgent need to develop more function-

This paper was funded by the research project of Rural Development Administration (PJ012607022019)

Received: June 5, 2020, Revised: July 15, 2020, Accepted: July 20, 2020

First author: In Kyoung Hong, inkyoung63@korea.kr, (1) https://orcid.org/0000-0002-7050-5413

*Corresponding author: Hyung Kwon Yun, yun0309@korea.kr, (10) https://orcid.org/0000-0001-9973-4706 
ally sustainable agricultural techniques in the field of urban agriculture (Hong et al., 2018). However, it is not easy to shed new light on the ancient agricultural techniques that had been accumulated based on experience and foreknowledge from a long time ago. Yet it is possible to improve the thoughts, experiences, means or methods that appear through the unchanging providence and principles with today's rational thinking. Inheriting traditional technology is not just sticking to the old ways but understanding the background and purpose, materials and techniques, as well as effects, and laying the groundwork to adequately use them from the contemporary perspective. Accordingly, this study selected Imwongyeongjeji by late Joseon Silhak scholar Seo Yu-Gu (1764-1845) as the data to examine traditional knowledge from the past. Imwongyeongjeji is known to be an encyclopedia focusing on agriculture, of which Bolliji is a comprehensive digest of arable farming overall, covering all fields necessary for urban agriculture such as utilization of water, soil property, farming period, reclamation and farming practices, sowing, harvest and storage. Thus, it will be suitable data for examining traditional agricultural technology. In particular, Gyeonjongbeop among traditional farming methods included in Bolliji is a farming method that has been acquired based on many years of experience. This farming method has sustainable potential value that includes ecological circularity and environmental friendliness.

Gyeonjongbeop is a traditional farming method introduced in Pungseok Seo Yu-Gu's Imwongyeongjeji, and it is a dry-field farming method that improved China's Daejeonbeop (Daitianfa) to be more suitable for Joseon. It is a furrow cultivation or furrow planting method invented to reduce damages from spring droughts. It is suitable for petty farmers and urban farmers, as it is effective in reducing labor and increasing productivity by cultivating wheat and barley. Since crops are planted in the furrows by making up for the deficiency of cultivating in level rows, there are shades and moisture that enable seeds to pop up easily in droughts as well. The method also has good heat conservation and thus easily leads to germination, and both weeding and earthing up are possible at the same time, which reduces labor. It is also efficient as fertilizers and manures can be applied intensively to crops only.
In addition, regular and constant sowing saves the seeds and makes ventilation more even, which evenly ripens the crops. Since roots are covered thickly with soil, the crops take roots deeply and are thus strong against winds and droughts, which is useful in cultivation. Above all, since it has the benefit of using the fallow land and making efforts during the winter off-season, there is an urgent need to implement this method to urban gardens. Accordingly, this study intends to examine how Gyeonjongbeop, which is the Joseon version of China's Daejeonbeop, is reinterpreted in Bolliji as a new technology that used old wisdom, suggest an objective contemporary garden model by reproducing the traditional farming methods included in old agricultural books, and apply this model to urban gardens based on the results of field application.

\section{Research Methods}

\section{Theoretical background}

This chapter set the traditional farming methods of the past as a concept of traditional knowledge and examined the process in which China's traditional farming method Daejeonbeop recorded in the Korean translation of Bolliji is interpreted as Gyeonjongbeop by Seo $\mathrm{Yu}-\mathrm{Gu}$ in terms of inheritance. We reviewed the process based on the design and application of Gyeongjeonbeop proposed by Seo $\mathrm{Yu}$-gu, examined its applicability, came up with parts that can be applied to urban agriculture, and suggested customized Jakmyobeop (how to make rows; how to make ridges) and cultivation method.

\section{China's Daejeonbeop}

The first record of Daejeonbeop is in the chapter Sikhwaji (the treatise on food and money) of Han Seo (Book of the Han; Ban, 2020) introduced in a Chinese agricultural book, which is presented as follows in the Korean translation of Bolliji (Seo, 2008).

"Zhao Guo became the Grain Intendant in the late years of Emperor Wu of Han Dynasty. Zhao Guo created Daejeon (Daitinfa, alternating fields system) 
with three furrows per myo (unit of crop field). The name Daejeon comes from the fact that the planting spot or site for crops is changed every year, and this is an old rule. Hou Ji first made furrows on fields. A furrow is made by two people plowing the field side by side with two plows in the width and depth of $1 \mathrm{chi}$ (unit of measurement, equals to $30.3 \mathrm{~cm}$ ) each. A furrow leads vertically to the end of 1 myo. There are 3 furrows in each myo, and thus 1 bu (100 myo) has 300 furrows. Sowing is done in furrows. After the sprouts leaf out, grass on the ridges is weeded little by little. In this process, the soil on the ridges is toppled and earthed up on the roots of young sprouts.

(Omitted)

In midsummer, the ridges are destroyed and the roots are deepened to endure the winds and droughts. Therefore, they become full and bountiful. The farming tools used in plowing, weeding and sowing seeds in Daejeon all have convenient techniques".

Daejeonbeop (Daitianfa) is a farming method developed by Zhao Guo during the years of Emperor $\mathrm{Wu}$ of Han and has the same meaning as Gujeon (qutian). Only the position of furrows is changed every year to cultivate crops and prepare for natural disasters such as droughts, floods, wind damages and cold-weather damage. Daejeonbeop, which is a 1-myo (a measuring unit for farmland marked as 30 pyeong [99.174 $\mathrm{m}^{2}$ ] in the Japanese colonial era but is currently banned from use) 3-furrow method, is used to reap good harvests (Fig. 1). However, this caused the issue of the sowing method in Joseon since farmland is wasted by using big plows and making wide ridges, and also because there is a huge gap in the growing speed of crops by scattering sowing instead of strip sowing.

\section{Seo Yu-Gu's Gyeonjongbeop}

Seo Yu-Gu, who intensified the research on Daejeonbeop so that it is settled in Joseon suitably according to the natural features, closely reviewed Daejeonbeop from ancient China left in historical records as well as Daejeonbeop accepted by Chinese agriculturists from Ming and Qing, and also Daejeonbeop that was implemented in Liaodong in the late Joseon period, after which he newly interpreted them and provided his own unique version of Daejeonbeop. This is based on China's Daejeonbeop and yet is an entirely new suggestion that is different from any other Daejeonbeop systems before. It is about shaping the field (Fig. 2) and was also referred to as Gyeonjongbeop, Gyeongjong-ji-beop, Gyeonjeonbeop and Gyeonjeon-ji-beop. Gyeonjongbeop in Bolliji is generally the same as Daejeonbeop: creating three furrows and three ridges at the width and depth of approximately $30 \mathrm{~cm}$ (1 chi) on 30 pyeong ( 1 myo) of the field that is about $182 \mathrm{~cm}(6$ chi) wide, and then strip sowing on the furrows. Seo Yu-Gu thought that it is necessary to create an environment in which crop roots growing in the furrows can grow out easily by deep plowing in order to implement the 1-myo 3-furrow method mentioned in Sikhwaji. He also created drainage channels between myos and even made bigger drainage channels around the field to prepare for the rainy season. Seo (2008) concretely described Gyeonjongbeop in culti-

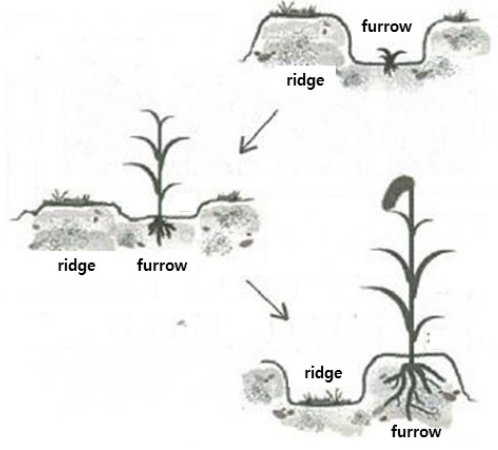

(A)

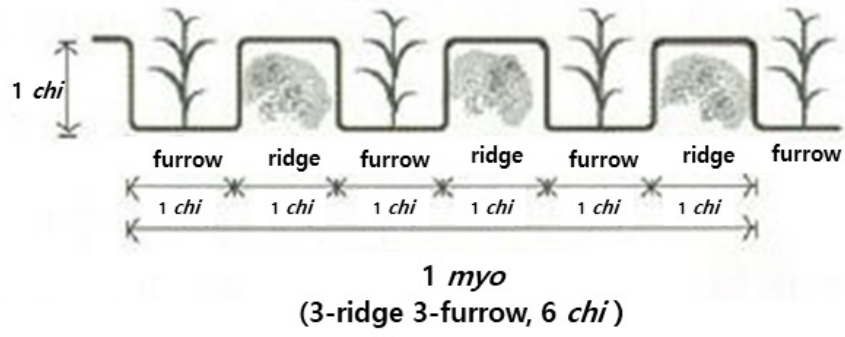

(B)

Fig. 1. Daejeonbeop of china, showing how the alternating fields system works (A) and the composition of 1 myo. Adapted from "Imwongyeongjeji. Bolliji", by Y.G. Seo, translated by M.H. Jeong and J.G. Kim, 2008, Seoul, Korea: Sowadang. 

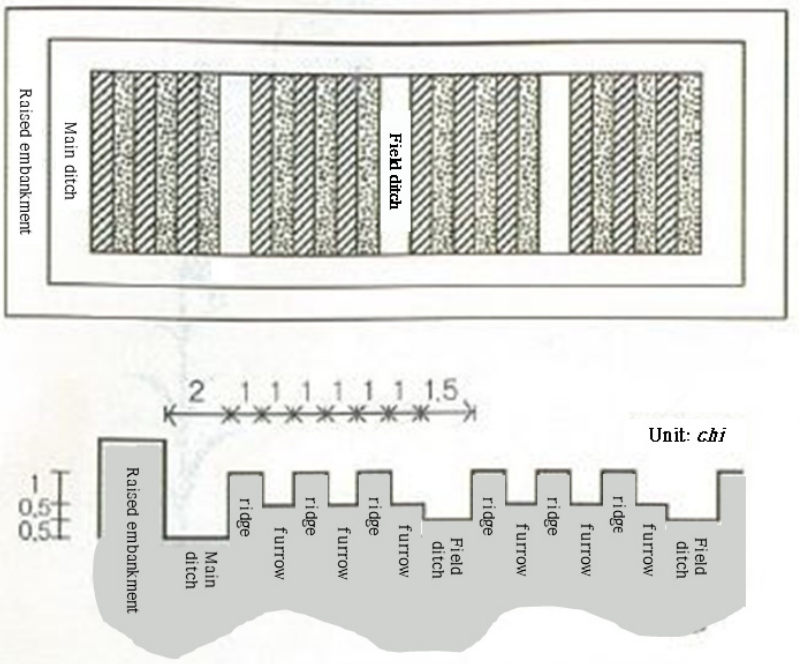

Fig. 2. Gyeonjongbeop, Seo Yu-Gu's new interpretation of Daejeon. Adapted from "Imwongyeongjeji. Bolliji", by Y.G. Seo, Translated by M.H. Jeong and J.G. Kim, 2008, Seoul, Korea: Sowadang.

vation of Hordeum vulgare var. hexastichon and Panicum miliaceum L. First, the entire farmland is deep plowed three times with a big plowshare in September and October, after which harrowing (puddling) is done six times to crush the soil. Then, a big ditch with the depth and width of 2 chi is dug up around the field using a spade. Small ditches with the depth and width of $45 \mathrm{~cm}(1.5 \mathrm{chi})$ are made horizontally inside the field every $182 \mathrm{~cm}$ (6 chi). In the next spring, three furrows are created in $182 \mathrm{~cm}$-wide (6 chi) rows with a small plowshare. Then, three furrows and three ridges are made (Fig. 3). This is the newly interpreted version by Seo Yu-Gu that suggests precise measurements unlike China's Daejeonbeop.

Moreover, Seo provided specific number of times each task is performed, such as deep plowing once and harrowing (puddling) three times, and laid stress on crops taking root and the drainage effect by creating drainage channels between rows. In particular, he insisted on using Gyeonjongbeop in cultivating Hordeun vulgare var. hexastichon. Moreover, drainage channels around the field were not mentioned since drainage channels can be made between rows (big myo). This implies that Hordeun vulgare var. hexastichon can endure spring rains even without the drainage channels on all sides. As such, Seo Yu-Gu was convinced that Gyeonjongbeop is the best dry-field

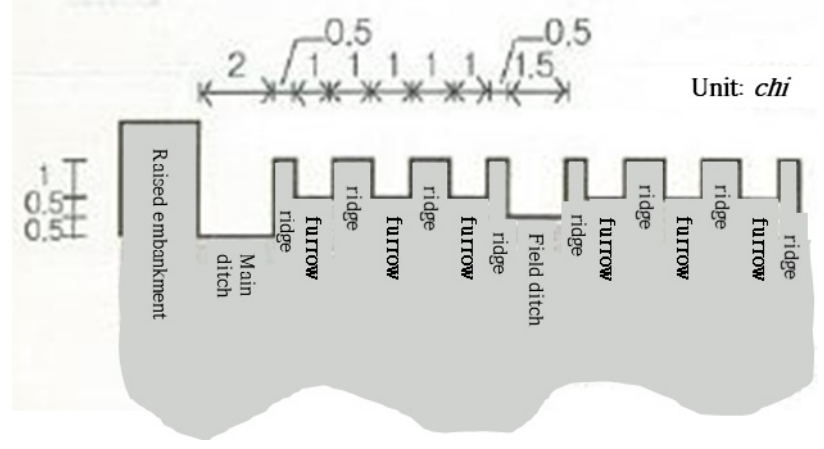

Fig. 3. Reconstructed Gyeonjongbeop for barleys and millets by Seo yu-Gu. Adapted from "Imwongyeongjeji. Bolliji", by Y.G. Seo, Translated by M.H. Jeong and J.G. Kim, 2008, Seoul, Korea: Sowadang.

farming method that must be accepted at the time in Joseon where intercropping (catch cropping) and double-cropping (two crops a year) are commonly used. Thus, while he did not precisely implement China's Daejeonbeop, he naturally created an opportunity to teach Panicum miliaceum L. farming method to Gyeonggi farmers as garrison farms so that he could establish a bridgehead to supply Gyeonjongbeop. Furthermore, he could newly interpret this into his own style of Daejeonbeop called Gyeonjongbeop by embracing and internalizing the discussions on Daejeonbeop. However, despite his enthusiastic efforts, Gyeonjongbeop failed to change the old customs of the private sector like intercropping and double-cropping, and thus ended up being a farming method that was merely an experiment of a few intellectuals including Seo Yu-Gu. Even though a firm, solid theory could be established by the experiment, it failed to have a great ripple effect to influence farmhouses because of the perception among farmers at the time, such as wastage of land due to idle ridges and burden of labor in shaping the fields.

\section{Utilization in modem urban agriculture}

The effective cropping system in the modern times is based on land management and cultivation technology that increases use of farmland and agricultural productivity. In particular, repeated cultivation (continuous cropping) that cultivates crops every year without idling the land is an efficient way of managing fields without fallow ground by establishing a consistent cropping system. Traditional farm- 

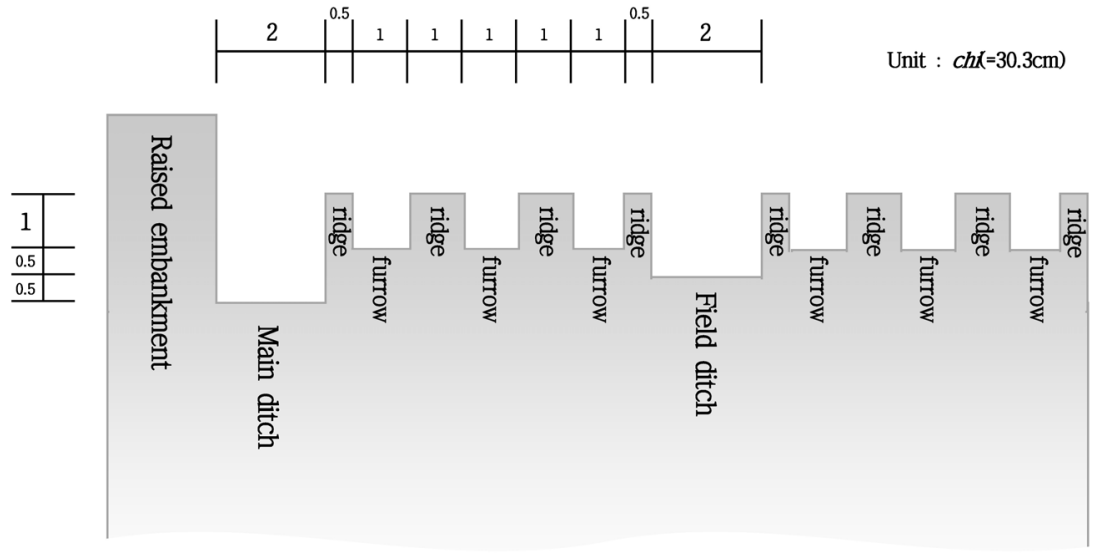

Fig. 4. Suggested urban farming method.

ing methods formed throughout many years are receiving attention as alternative agricultural techniques to ensure stability of agricultural products while constantly increasing agricultural biodiversity (Jeong et al., 2016).

Manjong (flatland sowing without making ridges and furrows), which is a conventional form of vegetable garden cultivation, has low germination rate and requires much labor in weeding. There is poor ventilation for crops as well due to uneven sowing, and fertilizing is also inefficient. Earthing up is also not possible in this method, which makes the crops vulnerable to winds and droughts. On the other hand, Gyeonjongbeop is a farming method that can solve all these problems; it is a response to climate change from on-ridge sowing to furrow sowing to reduce damage from spring droughts (Kim, 2010). Therefore, it is still highly appreciated among a few farmhouses that do not use machinery (Jeong, 2012). As such, Gyeonjongbeop is a farming method absolutely necessary for urban gardens, and its disadvantages mentioned in old agricultural books can be resolved by applying modern technology. Therefore, we reconstructed Seo Yu-Gu's jakmyobeop to better suit the modern times and suggested it as follows (Fig. 4). Here, the number of ridges and furrows could be adjusted according to the area required and the user's needs.

\section{Methods}

\section{Making a field}

Through the research on the topic, we set up the Gyeonjongbeop jakmyobeop that can be applied to urban gardens in the actual field. First, we deep plowed the entire field in September and softened the ground by harrowing (puddling) it multiple times, after which we shaped the field in all sides and created four ridges and three furrows. We created furrows to be width $30 \mathrm{~cm}$ and depth $25 \mathrm{~cm}$ based on historical research. Here, deep plowing is done because shallow plowing keeps the roots from properly growing out since the ground soil of the furrows is untilled; and crops can grow well only when the soil below the newly plowed ground is soft. Moreover, unlike Seo's field shape, we made the small ditches about $15 \mathrm{~cm}(0.5 \mathrm{chi})$ wider to facilitate water drainage (Fig. 5). This layout considers the field conditions depending on modern climate change. Here, the number of ridges and furrows can be adjusted depending on the area.

\section{Planting time, crops and survey method}

The field for Gyeonjongbeop in urban agriculture was designed to use both ridges and furrows unlike Seo Yu-Gu's Gyeonjongbeop. Based on the design, a field was plowed in August 2019 in the experimental field of National Institute of Horticultural and Herbal Science (NIHHS). After basic manuring, the field was created in early September. Seeds of Raphanus sativus var. longipinnatus (hill sewing), Brassica juncea var. integrifolia and Spinacia oleracea (strip sowing) were sowed as winter crops on the ridges on September 6, 2019. Compound fertilizers were applied after 2 weeks, and then additional fertilizers after 3 weeks for cultivation. Every other Thursday, growth of the crops such as above-ground weight, under- 


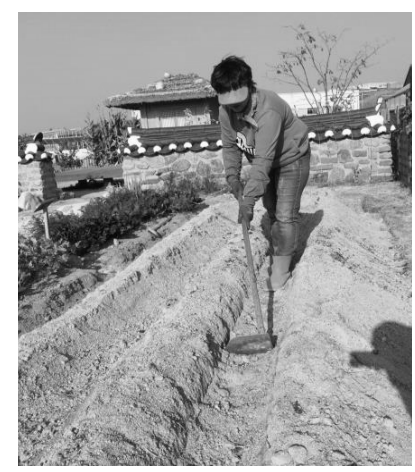

(A) Making a field

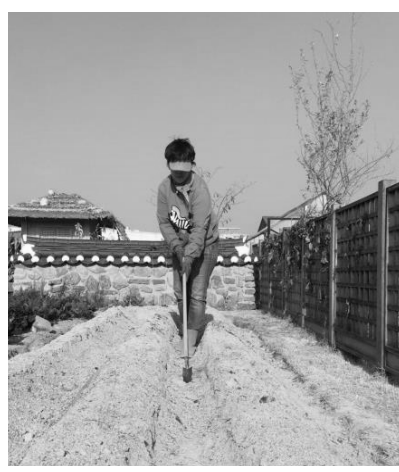

(B) Trimming the furrow

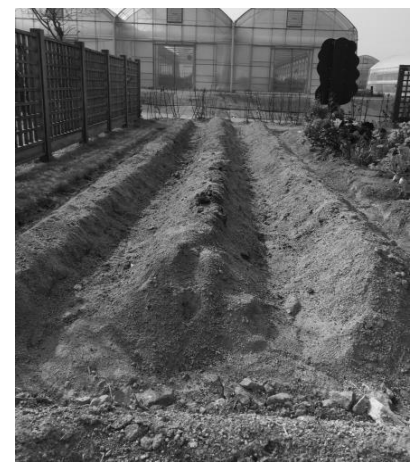

(C) Field completion

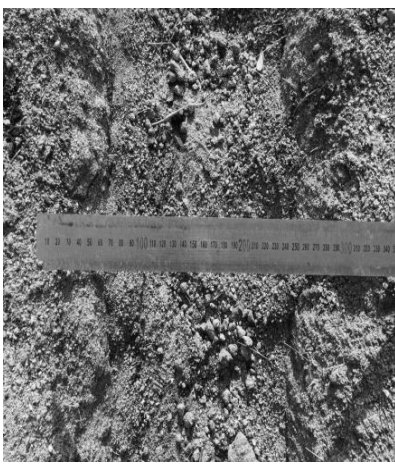

(D) Furrow width $30 \mathrm{~cm}$

Fig. 5. Preparing a field for planting.

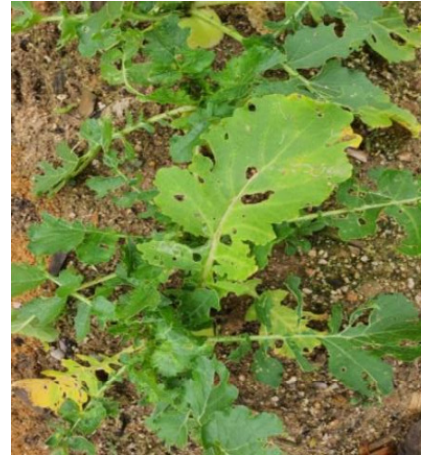

(A) Raphanus sativus

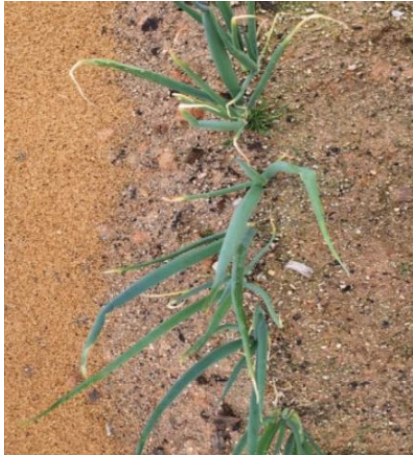

(B) Allium fistulosum L.

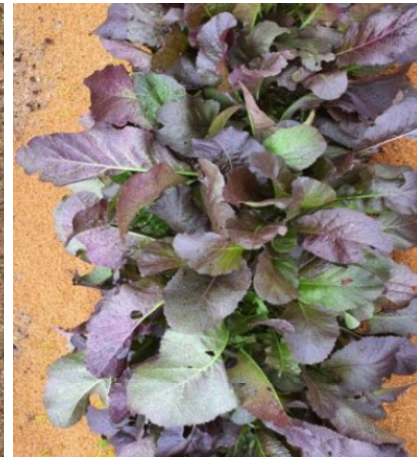

(C) Brassica juncea

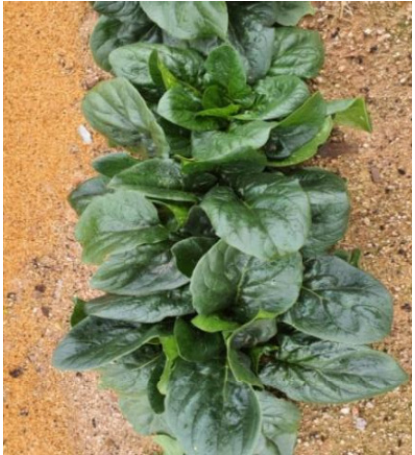

(D) Spinacia oleracea

Fig. 6. Photo of crops grown on ridges (photo taken on November 17, 2020).

ground weight and length (plant height) was examined three times repeatedly on two fields formed for each crop. Seedlings of Allium fistulosum L. were raised 2 weeks before and transplanted properly during the same period, after which growth of the crops including above-ground weight and length were examined. The winter crops were all harvested on December 9, which is Day 82 after planting.

For furrows, we sowed seeds of Triticum aestivum $\mathrm{L}$. and Hordeum vulgare var. hexastichon introduced as effective crops in Bolliji with strip sowing on November 6, 2019 and then covered them in rice husks for germination. Buds started to open on November 18, Day 12 after sowing, and the length and stem height were surveyed for 7 months until early June 2020 to verify the average state of growth of crops.

\section{Results and Discussion}

\section{Growth of vegetable crops on ridges}

We sowed seeds of Raphanus sativus, Brassica juncea, and Spinacia oleracea, and raised seedlings of Allium fistulosum L. and then transplanted them properly, after which we examined the growth of the crops on Day 60 and Day 82 (Tables 1-4). According to the report by Rural Development Administration (RDA, 2018b), the growth period of winter crops is 40-60 days. In this experiment, we surveyed the growth on the 60th day, which is the optimal harvesting time. Then, we cultivated the crops for 22 more days to determine the point in which they mingle with the upland crops growing on the furrows, compared their growth, and harvested them in early December when the sprouts of barleys shoot up on the furrows (Fig. 6). After sowing the seeds, the number of germinations was 
Table 1. Growth results of Raphanus sativus sowed on ridges

\begin{tabular}{|c|c|c|c|c|c|c|}
\hline \multirow{2}{*}{$\begin{array}{l}\text { Crop } \\
\text { No. }\end{array}$} & \multicolumn{3}{|c|}{ Day 60 after direct sowing $(n=18)$} & \multicolumn{3}{|c|}{ Day 82 after direct sowing $(n=15)$} \\
\hline & $\begin{array}{c}\text { Above-ground } \\
\text { weight (g) }\end{array}$ & $\begin{array}{c}\text { Underground } \\
\text { weight (g) }\end{array}$ & $\begin{array}{l}\text { Length } \\
(\mathrm{cm})\end{array}$ & $\begin{array}{c}\text { Above-ground } \\
\text { weight }(\mathrm{g})\end{array}$ & $\begin{array}{c}\text { Underground } \\
\text { weight (g) }\end{array}$ & $\begin{array}{l}\text { Length } \\
(\mathrm{cm})\end{array}$ \\
\hline 1 & 19.26 & 102.62 & 21.50 & 15.13 & 123.89 & 24.70 \\
\hline 2 & 40.50 & 207.25 & 27.70 & 28.15 & 218.02 & 28.30 \\
\hline 3 & 20.47 & 145.49 & 25.30 & 13.44 & 93.02 & 20.60 \\
\hline 4 & 15.76 & 90.68 & 24.00 & 23.17 & 234.19 & 27.10 \\
\hline 5 & 27.48 & 138.78 & 27.80 & 23.53 & 145.47 & 23.20 \\
\hline Total & 123.47 & 684.82 & 126.30 & 103.42 & 814.59 & 123.90 \\
\hline Average & 24.69 & 136.96 & 25.26 & 20.68 & 162.92 & 24.78 \\
\hline
\end{tabular}

Note. At the time of sowing, $\mathrm{n}=23$.

Table 2. Growth results of Brassica juncea sowed on ridges

\begin{tabular}{|c|c|c|c|c|c|c|c|c|}
\hline \multirow{2}{*}{$\begin{array}{l}\text { Crop } \\
\text { No. }\end{array}$} & \multicolumn{4}{|c|}{ Day 60 after direct sowing $(n=83)$} & \multicolumn{4}{|c|}{ Day 82 after direct sowing $(n=77)$} \\
\hline & $\begin{array}{c}\text { Above-ground } \\
\text { weight (g) }\end{array}$ & $\begin{array}{c}\text { Length } \\
(\mathrm{cm})\end{array}$ & $\begin{array}{l}\text { Leaf length } \\
(\mathrm{cm})\end{array}$ & $\begin{array}{l}\text { Leaf width } \\
\quad(\mathrm{cm})\end{array}$ & $\begin{array}{c}\text { Above-ground } \\
\text { weight }(\mathrm{g})\end{array}$ & $\begin{array}{l}\text { Length } \\
(\mathrm{cm})\end{array}$ & $\begin{array}{l}\text { Leaf length } \\
(\mathrm{cm})\end{array}$ & $\begin{array}{l}\text { Leaf width } \\
(\mathrm{cm})\end{array}$ \\
\hline 1 & 65.81 & 34.50 & 33.70 & 12.40 & 86.52 & 39.10 & 12.50 & 43.70 \\
\hline 2 & 45.89 & 36.80 & 34.60 & 9.50 & 215.80 & 41.70 & 16.00 & 49.10 \\
\hline 3 & 71.35 & 37.70 & 33.50 & 10.70 & 224.64 & 45.60 & 16.80 & 52.00 \\
\hline 4 & 54.50 & 41.20 & 40.80 & 12.00 & 109.46 & 41.00 & 13.10 & 44.30 \\
\hline 5 & 42.31 & 33.80 & 33.50 & 9.50 & 90.27 & 39.40 & 11.80 & 41.50 \\
\hline Total & 279.86 & 184.00 & 176.10 & 54.10 & 726.69 & 206.80 & 70.20 & 230.60 \\
\hline Average & 55.97 & 36.80 & 35.22 & 10.82 & 145.34 & 41.36 & 14.04 & 46.12 \\
\hline
\end{tabular}

Note. At the time of sowing, $\mathrm{n}=88$.

8 to 11 for each crop. As a result of examining the growth of crops after harvest in comparison with the conventional culture reported by RDA (2018b), the above-ground weight of Raphanus sativus decreased by $4 \mathrm{~g}$ on average compared to the optimal harvesting time, but the underground weight that is actually used increased by $26 \mathrm{~g}$. The above-ground growth of Brassica juncea (mustard) increased by $89 \mathrm{~g}$ on average compared to the optimal harvesting time, and the length increased by $4 \mathrm{~cm}$ and leaf width by $35 \mathrm{~cm}$, whereas the leaf length decreased by $21 \mathrm{~cm}$. The above-ground growth of Spinacia oleracea increased by $21 \mathrm{~g}$ on average compared to the optimal harvesting time, and the length increased by $0.16 \mathrm{~cm}$ and leaf width by $1.94 \mathrm{~cm}$, whereas the leaf length decreased slightly by $0.08 \mathrm{~cm}$. The above-ground growth of Allium fistulosum L. increased by $6.7 \mathrm{~g}$ on average compared to the optimal harvesting time, and the length also increased by
$4 \mathrm{~cm}$. Winter crops are short and thus can be harvested in late fall to early spring with simple heat retention, thereby proving the efficient use of Gyeonjongbeop in which vegetables can be cultivated in empty gardens.

\section{Growth of upland crops on furrows}

Hordeum vulgare var. hexastichon that germinated on Day 12 after direct planting on November 18 was $1.9 \mathrm{~cm}$ and Triticum aestivum L. was $1.7 \mathrm{~cm}$. The ears of Hordeum vulgare var. hexastichon were formed in late April 2020, and the ears of Triticum aestivum L. were formed in early May 2020. The average growth results of each crop are as shown in Fig. 7, and it was carried out in early to mid-June, which is the same as the conventional culture harvesting time of Hordeum vulgare var. hexastichon suggested by RDA (2018a). 
Table 3. Growth results of Spinacia oleracea sowed on ridges

\begin{tabular}{|c|c|c|c|c|c|c|c|c|}
\hline \multirow{2}{*}{$\begin{array}{l}\text { Crop } \\
\text { No. }\end{array}$} & \multicolumn{4}{|c|}{ Day 60 after direct sowing $(n=36)$} & \multicolumn{4}{|c|}{ Day 82 after direct sowing $(n=32)$} \\
\hline & $\begin{array}{c}\text { Above-ground } \\
\text { weight }(\mathrm{g})\end{array}$ & $\begin{array}{l}\text { Length } \\
(\mathrm{cm})\end{array}$ & $\begin{array}{l}\text { Leaf length } \\
(\mathrm{cm})\end{array}$ & $\begin{array}{l}\text { Leaf width } \\
\text { (cm) }\end{array}$ & $\begin{array}{c}\text { Above-ground } \\
\text { weight (g) }\end{array}$ & $\begin{array}{l}\text { Length } \\
(\mathrm{cm})\end{array}$ & $\begin{array}{l}\text { Leaf length } \\
(\mathrm{cm})\end{array}$ & $\begin{array}{l}\text { Leaf width } \\
\text { (cm) }\end{array}$ \\
\hline 1 & 31.11 & 18.50 & 18.00 & 8.70 & 54.94 & 19.00 & 18.20 & 11.70 \\
\hline 2 & 36.92 & 19.50 & 18.80 & 9.70 & 60.52 & 21.20 & 19.10 & 11.50 \\
\hline 3 & 47.79 & 21.90 & 21.00 & 11.10 & 40.27 & 19.80 & 19.50 & 10.20 \\
\hline 4 & 34.24 & 19.30 & 18.80 & 10.20 & 91.97 & 22.20 & 21.50 & 13.80 \\
\hline 5 & 33.22 & 20.00 & 19.20 & 7.60 & 43.66 & 17.80 & 17.10 & 9.80 \\
\hline Total & 183.28 & 99.20 & 95.80 & 47.30 & 291.36 & 100.00 & 95.40 & 57.00 \\
\hline Average & 36.66 & 19.84 & 19.16 & 9.46 & 58.27 & 20.00 & 19.08 & 11.40 \\
\hline
\end{tabular}

Note. At the time of sowing, $\mathrm{n}=42$.

Table 4. Growth results of Allium fistulosum L. sowed on ridges

\begin{tabular}{|c|c|c|c|c|}
\hline \multirow{2}{*}{$\begin{array}{c}\text { Crop } \\
\text { No }\end{array}$} & \multicolumn{2}{|c|}{ Day 60 after direct sowing $(n=28)$} & \multicolumn{2}{|c|}{ Day 82 after direct sowing $(n=24)$} \\
\hline & Above-ground weight (g) & Length (cm) & Above-ground weight (g) & Length $(\mathrm{cm})$ \\
\hline 1 & 14.48 & 33.00 & 19.96 & 42.20 \\
\hline 2 & 22.85 & 38.30 & 17.82 & 37.00 \\
\hline 3 & 14.26 & 37.20 & 27.59 & 37.10 \\
\hline 4 & 22.29 & 38.00 & 39.71 & 45.40 \\
\hline 5 & 16.92 & 36.70 & 19.58 & 43.00 \\
\hline Total & 90.80 & 183.20 & 124.66 & 204.70 \\
\hline Average & 18.16 & 36.64 & 24.93 & 40.94 \\
\hline
\end{tabular}

Note. At the time of sowing, $\mathrm{n}=32$.

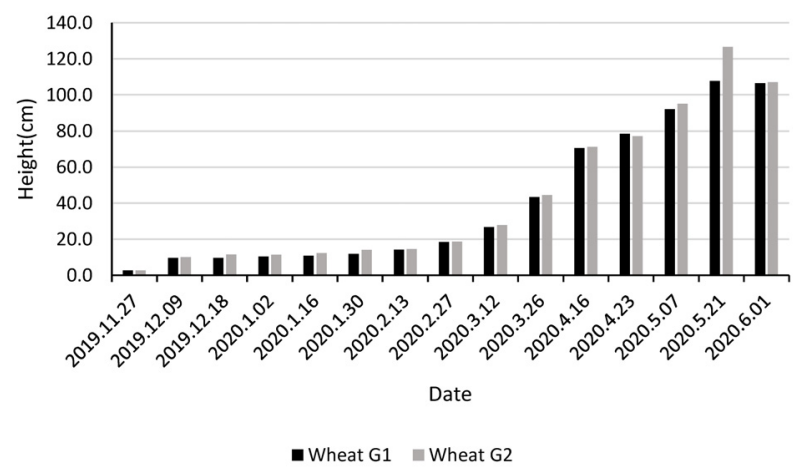

(A) Triticum aestivum L.(wheat)

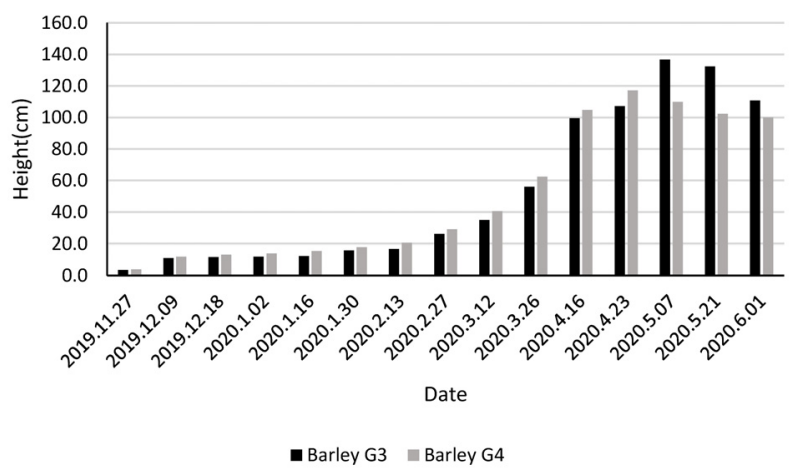

(B) Hordeum vulgard var. hexastichon (barley)

Fig. 7. Growth result of Triticum aestivum L. (A) and Hordeum vulgard var. hexastichon (B).

Glutinous Triticum aestivum L. used in this study is a variety nurtured by RDA in 2012, and its ripening period is early June. Its stem height is less than $80 \mathrm{~cm}$ and it is resistant to lodging. The results of this study also showed the stem height of less than $80 \mathrm{~cm}$, which is the same as the results of RDA (2015), and Triticum aestivum L. was matured and harvested in 210 days on June 11, which was sooner than the report by Rural Development Administration that it requires approximately 260 days in Suwon.

The ripening period of Hordeum vulgare var. hex- 


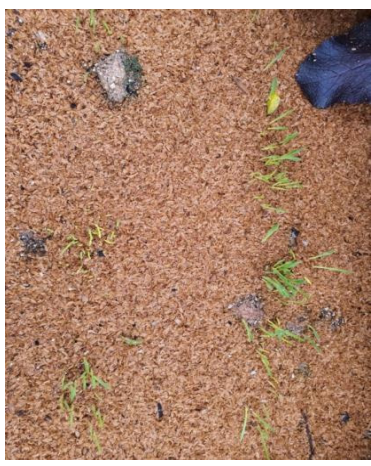

(A) Hordeum vulgard var. hexastichon germination

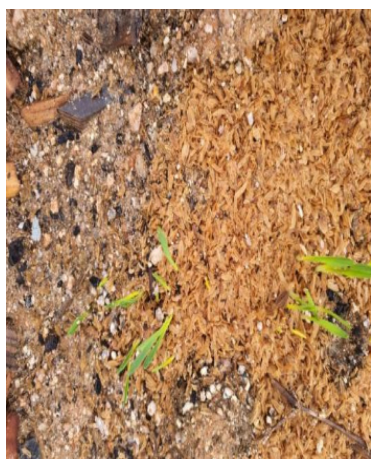

(B) Triticum aestivum $\mathrm{L}$. germination

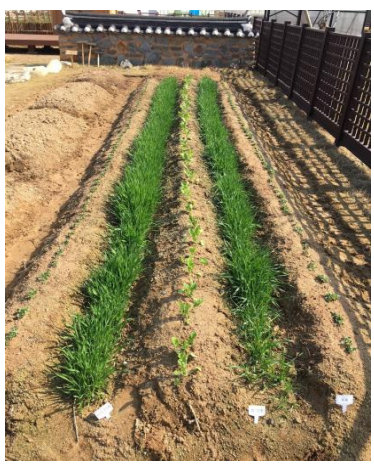

(C) Cultivation

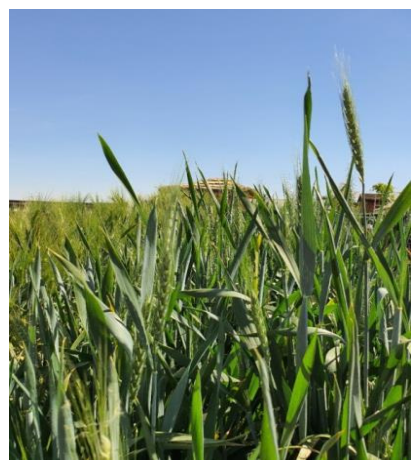

(D) Ears of Triticum aestivum L. and Hordeum vulgard var. hexastichon

Fig. 8. Photo of crops grown on furrows.

astichon is around June 5 in Suwon, and its length is about 60-100 cm. In this experiment, we harvested Hordeum vulgare var. hexastichon on June 1, which is 4 days earlier than the base area, and the length was $105 \mathrm{~cm}$, which is slightly longer than the result of conventional culture in RDA (2018a; Fig. 8). This is due to the warm weather of the southern region. This proved that this Jakmyobeop can make up for the deficiencies of Hordeum vulgare var. hexastichon cultivation that concerned Seo Yu-Gu, such as being weak against winds and cold, easily destroyed by the spring rains, and not properly flourishing.

As such, modern Gyeonjongbeop that can use both ridges and furrows can efficiently increase the use of gardens and improve productivity, and also enables use of gardens in winter, thereby being a customized farming method for urban agriculture. In particular, by sowing on the ground, farm products cultivated on the furrows are kept warm and easily germinated, and they have deep roots by earthing up, thereby well enduring winds and droughts. Moreover, both weeding and earthing up are possible at the same time without much labor, thereby resolving the issue of labor raised in the Joseon period. In addition, fertilizers can be applied intensively only on crops, which increases efficiency. It is an effective farming method that meets the needs of urban dwellers as urban gardens can be used as farms. This will further activate and promote urban agriculture and help create a sustainable and healthy green environment.

\section{Conclusion}

Traditional agricultural technology formed throughout many years is receiving attention with the growing interest in environment-friendly agriculture. It is acknowledged as an alternative agricultural technique that can efficiently operate and manage gardens while also constantly increasing agricultural biodiversity. This study is to find a customized garden management plan based on the benefits of using the fallow land and making efforts during the off-season by modernizing Gyeonjongbeop, one of the traditional farming methods from the late Joseon period.

Gyeonjongbeop is a traditional farming method introduced in Imwongyeongjeji written by Pungseok Seo $\mathrm{Yu}-\mathrm{Gu}$. It is a dry-field farming method that improved China's Daejeonbeop to better suit the conditions in Joseon. It adopts furrow cultivation or furrow planting as a response based on the little ice age designed to reduce damages from spring droughts. It is effective in reducing labor and increasing crops by cultivating Triticum aestivum $\mathrm{L}$ and Hordeun vulgare var. hexastichon and thus is a suitable method for petty farmers and urban farmers. This method makes up for the deficiencies of cultivating on level rows as an empirical agricultural method with proved utility and scientific accuracy among many traditional agricultural techniques recorded in old agricultural books. Accordingly, we analyzed data based on ancient agricultural books and reconstructed them according to our conditions, ultimately proposing a customized design plan. This indicates that the traditional farming method proposed 
to help farmers in the late Joseon period is a customized method that can promote a system in urban agriculture by organizing and delivering familiar information more systematically. It can also preserve and supply the traditional values through urban agriculture by using traditional knowledge in addition to popular knowledge. Moreover, the humanistic value of urban agriculture can be increased by applying the traditional farming method with cultural and historical context. A highly efficient cropping system can be operated by using gardens without a resting period and anticipating increased harvest. In fact, as a result of applying this method to an actual garden and testing the growth of crops, it was found that the crops showed growth almost the same as general crops, thereby proving the strength in vegetable garden management using fallow lands.

This study has its limitations in conducting the experiment only on winter crops and coming up with results using only the experimental plot without testing hypotheses. Further research must establish a cropping system for garden crops that can be run year-round by plowing the fields after harvest and cultivating other crops, and prove the excellence of Gyeonjongbeop with objective verification by comparing with the control plot. This will verify the potential utility value of Korean traditional agricultural technology and increase completeness of the traditional vegetable garden model. In addition, applying historical knowledge to modern urban gardens will help increase completeness of the garden model and expand the base of people that intend to participate in urban agriculture.

\section{References}

Ban, G. 2020. Han Seo, Zi 1 [Book of Han, Aspiration 1].
Vol. 24-25. (H.W. Lee, Trans.) Seoul, Korea: 21st Century Books.

Guh, J.O. 2009. Up-to-date significance of Korean conventional agriculture. Korean J. Agric. Hist. 8(3):157-207.

Hong, I.K., Y. Chae, Y. Jang, S.M. Lee, and J.N. Su. 2018. Analysis of urban agricultural effects by factors according to the urban citizens income level: Socially sustainable effect, negative effect, and economically sustainable effect. J. People Plants Environ. 21(6):461-471. http://doi.org/10.11628/ksppe.2018.21.6.461

Jeong, M.C., S.J. Kim, and H.Y. Mun. 2016. The valuation of traditional agricultural technology for modern utilization: Focusing on traditional knowledge in old agriculture book. J. Namdo Folklore Res. 33:207-238. Retrieved from http://www.namdofolk.net

Jeong, M.H. 2012. The historical study of the discussions on the dissemination of Kyunjong-beop in the Joseon Dynasty. Korean J. Agric. Hist. 11(2):27-60.

Kim, J.H. 2010. Characteristics of agriculture in late Chosun and its eco-climatological background. Asian Comp. Folklore 41:97-127. Retrieved from https://www.bigyo minsok.org

Park, S.K. 2004. A case study of Cuba's organic agriculture management. Master's thesis. Korea University, Seoul, Korea.

Rural Development Administration. 2015. Wheat. Agricultural Technology Assistant 44. Wanju, Korea: Author.

Rural Development Administration. 2018a. Barley. Agricultural Technology Assistant 118. Wanju, Korea: Author.

Rural Development Administration. 2018b. Leafy vegetables. Agricultural Technology Assistant 140. Wanju, Korea: Author.

Seo, Y.G. 2008. Imwongyeongjeji. Bolliji (M.H. Jeong and J.G. Kim Trans.). Seoul, Korea: Sowadang. 